\title{
The Compass of Beauty A Search for the Middle
}

\section{Lars Spuybroek}

A very specific problem occurs at the heart of ontology: how can things exist externally, with others, while being made up of parts, and thus existing internally? Or, to phrase it a bit more poignantly, in Kantian terms: how can things have synthetic relations between the whole and the world while being constituted analytically, through relations between the whole and its parts? How can these two realms be part of one continuum of existence? No variety of materialism has been able to solve this problem. In its traditional form, determinism, either God or consciousness is needed to direct the connecting vector of necessity; and its later form, emergence, leaves a gap between the interacting parts and the emerged whole happily interacting with other wholes. Even in the nineteenth century, Darwin struggled with the idea that variation acted as the sole positive force in nature, "endlessly" adding "forms most beautiful," ${ }^{1}$ with natural selection doomed merely to act as a negative force, selecting out some of those variants as ugly misfits. Indeed, fitness in itself contributes nothing to the concept of variation, since it is not the environment that tells parts how to come together. Apparently, parts only interact with parts and wholes with wholes, and while materialist ontologies succeed very well in explaining the intensive parts stage and the environmental wholes stage, they completely fail to connect the two. The two physical sides of the equation are separated by a yawning metaphysical gap, impossible for them to bridge, at least physically. A brief reflection on the vertical nature of the term "emergence," however, should make us realize that the flat, blind world of material interactions cannot exist without transcendence. Scientists and philosophers of science speak of emergence as if it is the reverse of classic top-down imposition, and it is, but merely in directionality, certainly not conceptually: it inhabits the same vertical axis, covers the same vertical distance, and thrives on the same dualisms. Without question, admitting to the metaphysical nature of emergence would deeply affect all notions of physicality, which is why all materialists shy away from it. Therefore, we should find a way to accept transcendence and, instead of making it part of external agency, make it part of things themselves.

To do so, we would first need to put enough mind into matter to allow the parts to see beyond their own horizon. We should come to understand their efforts to conform as an actual striving for a whole, which amounts not to a general teleology, like the abovementioned necessity, but rather to a local teleology, or what we might call a local transcendence. Then, inversely, we should allow wholes to connect to parts of other wholes, turning that local transcendence into a zone of attraction. My claim is 
that only beauty makes this reversal possible. It makes the parts exceed the whole, rather than the whole exceeding the parts, as the doctrine of emergence prescribes. When you say someone has beautiful eyes, you do not expect the other to take out an eye and hand it over, as Baudrillard once joked. The parts of other people or things that we like-somebody's red hair, the shining of gold, the curves of the hills, the light flickering on the river-we do not like as such, but as parts of a whole, as radiating from that whole. ${ }^{2}$ And at that point, the part has transcended its role as a part. The red hair might insulate the scalp from the cold, but our liking has no interest whatsoever in that physiological function. Natural selection will never be able to explain why redness came about in the way that emergence can, but emergence will never be able to explain why redness is liked-they pass each other like ships in the night. Beauty allows parts to be visible and available to other wholes without removing them from their relationship with neighboring parts. Philosophically speaking, this is unheard of: no other power is capable of jumping over the proverbial gap between the two realms. Beauty - and it is no accident that Darwin used the word-solves that impossible equation and manages to put the analytic and the synthetic in the same realm of existence, or at least to find a point where they intersect or align, or even pivot when we think of it as a reversal: a point that is necessarily ontological. Things cannot be without being beautiful; or, to put it somewhat more neutrally, things cannot be without making a claim on their environment, no matter what that claim is. Beauty is like the narrow middle of an hourglass, with all parts gathering into a single point on the convergent side and spilling out on the other, divergent side, as if radiating from that point. Our question in the next twenty or so pages should then be: How does beauty construct this intersection between the two states?

Traditionally, this point has been termed a "middle," a middle that has taken on so many forms that it may be useful to roughly sketch its historical transformations before we enter into a more detailed discussion. A good place to start would be Apollo's call for moderation, which later developed into Aristotle's virtuous golden mean, and in between, Plato's monopolar universe where beauty occupied the absolute center of everything. This concept raises some questions right away: does it mean that beauty is itself the middle-like a heart or an origin —or that it must exist between preexisting extremes that have not yet been mentioned? Plato was rather ambiguous on the matter, since in his philosophy beauty plays the role of the good yet is as often described by him in terms of the terrifying, such as a bolt of lightning that strikes from the sky. Apparently, his singular pole secretly leads a double existence. A few centuries after Plato, lightning became the model Longinus used to postulate his notion of the sublime in the Peri Hypsous: the claim of things not to a middle position but to the greatest and the highest. For more than a millennium, the universe of aesthetics has remained in this bipolar state, oscillating between beauty and the sublime, though occasionally other forms are admitted - the novel, the strange, the comic, the tragic-mostly in the form of subcategories. The first notion of beauty and the sublime being connected by a continuous scale of gradual transformations - as if by a slider, so to speak-may have come with the invention of the picturesque, famously described by Uvedale Price as "a station in between beauty and sublimity." As is well known, Kant carefully follows the English aestheticians in their theories, while adding more positions to the slider and shifting beauty slightly toward the middle by introducing the pretty (Hübsch) on one extreme and the sublime on the other, with the magnificent and the terrifying (Schreckhaft-Erhabene) in between. Dilthey, the German neo-Kantian philosopher, in 
turn, managed to add the ugly to the lineup as well, and was the first to call the system a spectrum. Following this hint on color, it was Max Dessoir who then constructed a diagram of aesthetics in the form of a color wheel, a spoked circle, finally bending the linear spectrum into a curved systemacy. At that point, it was not clear to Dessoir how the circle in fact reintroduced the concept of a middle on a new level: as a center, not as the midpoint on a line. At last, in the 1970s, the American process philosopher Charles Hartshorne, by then a septuagenarian (though with another thirty years ahead of him), mixed Dessoir's model with Whitehead's ideas on beauty to form a very precise biaxial model while placing beauty back at the center, creating a middle between two dimensions, between two sliders - one analytical, indexing the relations between parts, and the other synthetic, indexing relations between wholes. At that point, almost 2,500 years had passed since Plato had expressed his ideas on beauty.

Describing the course of beauty through history, even in such a sketchy fashion, immediately challenges a facile concept of the middle, demanding a far more rigorous definition that will allow us to understand the variations and how these might have evolved from one another. In some of these historic phases, the term "middle" referred to moderation and mediation; sometimes it indicated a mean; and sometimes it was used in the sense of an equation. However, in this apparently confusing lineage we discern a clear increase in dimensionality, going from Plato's universal center point to an ever-widening linear scale, then transforming into a circular surface defined by a center and a circumference. Naturally, during each of these phases, questions arise. For instance, looking at its linear phase, should we view the middle as a pivot between two ends of a scale? That would mean the middle was fixed and the extremes were variable. Or should we view the poles as fixed, with a sliding midpoint between them, which things could seek out through variation? The first would probably best be called an equation, the second a mediation. Strangely enough, the continuous blurring of concepts itself seems to have increased the dimensionality of the system. The single point transforms into a single line with two poles, and that single line into two lines (now with four poles), each stage defined by its own notion of a middle, be it a center, a form of mediation or an equation. We should not only be questioning what exactly constitutes a middle but also asking ourselves what it is whose middle we are speaking of, since throughout its history beauty has been surrounded by ever more diverse aesthetic values. Does this mean beauty is positioned in a world that consists of states that are not beautiful? Yes, in a way. And when such states are not beautiful, are they still part of that pivoting function, that ontological function that we have assigned to beauty? Yes, probably. And if so, does that mean those other states are related to beauty in a way in which they are not related to each other? Yes, it certainly would.

At the moment when we start to view beauty as fundamental to existence, we are able to understand the variable powers of the analytic and the synthetic as they merge in entities, spawning things that are not only beautiful but, just as often, ugly, magnificent, cute or funny, if not hilarious or ridiculous, or even quirky and quaint, cool, boring or weird, melodramatic and vulgar, or again totally common and ordinary, not forgetting of course horrific and terrifying, or utterly gruesome and disgusting - and many, many more things. Such ontological abundance means in the first place that all things are positive: all things act in the arena of presence, an arena deprived of any backstage area, basement, or curtains to hide behind. Things can be withdrawn, autistic or melancholic, but they are so in the light of day. In the second place, it means all positive things are equations of the analytic and the synthetic, both axes producing 
positive values somewhere between zero and a maximum. And, since the synthetic deals with the configuration of presence-all wholes interacting with one another at a certain moment-it also means, in the third place, that such a snapshot fills the complete mosaic of beauty in all its variations. It forms a universe where every fragrant flower, every smile on a face, every bomb attack, every nightmare, every tumor and every silly joke seems to be part of a massive kaleidoscopic image in which the heaviest stone monument and the tiniest reflection, a flash of red hair and a plane crash, the most fragile dragonfly and the darkest forest all mosaically fit together at every instant, constantly aggregating into enormous multicolored crystals, which immediately collapse to be replaced with new generations; and this kaleidoscopic image is beyond what anyone of us would call order, or chaos for that matter, passing a threshold at which sheer contingency and pure perfection are wholly interchangeable.

Let us now take our little sketch and, step by step, add more detail.

\section{Spectrum and Circle}

The ancient, colossal statue of Apollo on his island of birth, Delos, carried in one hand his famous bow and in the other a second, much smaller statue of the Three Graces, mounted on a disk. Though a frequently used way of depicting Apollo's dual nature in ancient Greece, this iconography is no longer commonly known, since most statues have not survived intact and only a handful of engravings on ancient coins and descriptions in ancient manuscripts remain. Apollo's better-known attributes, the bow and the lyre, fulfilled similar functions, though more ambivalently, since in ancient Greece the two were clearly connected. For example, Heraclitus used the bow and the lyre to illustrate his celebrated doctrine on the harmony of opposites, ${ }^{3}$ later developed into concordia discors, the maxim of the Renaissance. Aside from the formal resemblance between bow and lyre, there is the conceptual one: the string of a bow can "sing sweetly," as Homer wrote, ${ }^{4}$ and the music of the lyre can strike at our hearts with the sharpness of an arrow. The classical philologist Karl Kerényi argued that Apollo could not be adequately characterized by the customary loftiness ascribed to him but combined chthonic darkness and Olympian clarity in one divinity. ${ }^{5}$ In a similar vein, the classicist Marcel Detienne speaks of Apollo's "profound ambivalence," especially because he had more killings to his name than any other god. ${ }^{6}$ Apollo was capable of "striking from afar" (bekebolos) with his arrows as well as enchanting and persuading with his music or his tongue. In other words, Apollo's dual nature is not so much a question of choice, of either/or, but of a combination, a doubling of the dimensions in which each of his actions takes place.

In light of this, we should be quick to distance ourselves from the depiction of Apollo as the tedious, teetotaling, proto-Christian anti-Dionysus that the early Nietzsche made of him in The Birth of Tragedy. The young philosopher crudely located Dionysus at one end of the spectrum and Apollo on the other, as if the first were interested only in excess and the second merely in harmony. Apollo's temple in Delphi was in fact shared with the Dionysus cult. In winter the temple was used to dedicate services to Dionysus, but the rest of the year the priestess— the Pythia—was in regular but frenzied communication with Apollo through epiphanies that were at least as ecstatic as those of the god of wine and spirits. Certainly, Apollo's maxim-méden ágan ("nothing in excess"), inscribed above the entrance to the temple in Delphi-is a call for 
moderation, but we have to keep in mind that moderation is always one of excess. Apollo's call is not one for abstinence: he does not propose to counter excess with asceticism or passivity; that would lead absolutely nowhere. We should understand that excess and moderation are not of the same order and that we cannot just stop halfway toward excess. We cannot simply interrupt ourselves, nor can we divide ourselves in two, into a rational, moderating mind and a body thirsty for excess, since the mind would quickly concede during any ecstatic act. No, it would be much better to imagine excess and measure as two forces coming from different directions. And those two forces need to be mediated: they can only be resolved through one act. In this case, a single act does not subsist in doing one thing until the point of exhaustion. The act needs to follow a curved trajectory: to start in one direction and come to a close in another. A single act - that is, an act of beauty - does two things simultaneously. First it aims for excess, then it aims for moderation, or, to use the metaphor of Apollo's bow, it shoots the arrow upward while aiming forward. With this model, we are shifting the notion of mediation toward that of mathematical equation: between the horizontal axis of measure and the vertical axis of excess, Apollo draws a curved function, equating the influence of both, starting with more verticality and ending with horizontality.

Doing something well, or, as Aristotle would say, doing something virtuously, then becomes a form of navigation, in which we do not move in one direction but steer between multiple directions. This, of course, we recognize from Plato's analogy of the charioteer in the Phaedrus, where the soul is represented by a chariot pulled by two winged horses, one black and the other white. Plato's analogies - the cave, the ladder of love, the charioteer-are not just metaphors, as often indicated, but closer to mathematical functions, and it is no accident that in many translations they are clarified with concise diagrams. In fact, it would not be wholly off the mark to call Plato the first analytic philosopher, since those analogies could easily be written out in mathematical symbols. (His notion of truth was deeply influenced by Pythagorean equations.) Anyway, the brilliance of the analogy of the charioteer lies in the fact that the vector of an act can be separated into two forces, or, more precisely, two sets of variables, since each horse can exert anything between minimum and maximum force. And since the horses are winged, the chariot can go up, down, left or right. It is quite clear from Plato's descriptions in the Phaedrus that the steering cannot be reduced to the mere imposing of one's will on both horses-if that were the case, the soul would not need the horses to strive. On the contrary, Plato describes a myriad of behaviors: zigzagging through the sky, falling back to earth, and steering one's way up to the sphere of immortality to become part of the ever-recurring cycles of the heavenly bodies. The soul, as Plato sees it, is not the charioteer steering the body as a homunculus but the single movement between two directions. Slightly earlier, when writing the Symposium, he used the term metaxu for this in-between, a term which becomes especially important in the dialogue between Diotima- "a woman from Mantinea"-and Socrates, as she teaches him about the nature of love as it relates to beauty.

"Love is of beautiful things," 7 she says, which means: not yet possessing beautiful things but being in a state between not having and having beauty, a state that cannot be described as a static betweenness but as a being-under-way, a state of striving and navigating. In this sense, all acts are acts of love because they strive for beauty, and such acts coordinate themselves between two feelings: one of sheer happiness ${ }^{8}$ and one of pure fear, a fear of falling in which one moves in the opposite direction along the vertical axis of transcendence toward doom and failure. This double movement of love 
is taken up again in the Phaedrus after the analogy of the charioteer, when he arrives at the moment of possession, falling in love with a beautiful boy whose face strikes him like "a bolt of lightning"; 9 it is a love that makes the soul "begin to grow wings." ${ }^{10}$ And, as often in Plato, it presents a dual argument that floats between stillness-we should bear in mind that the charioteer actually stands still in his chariot-and movement, between wisdom and ignorance, but here especially between overpowering and empowering. We are "captured by beauty" while "a fear comes over us,"11 a power that comforts us as much as it terrifies us, and one that he as often associates with a bolt of lightning as with the brilliance of the sun.

In Plato, we are not only introduced to this vast cosmic system of heavenly verticality and earthly horizontality but also to this confusion of beauty-as-the-highest and beauty-as-the-middle. And the confusion sometimes tends to take hold of the pages and spread like a stain. For example, Plato is adamant about the ontological nature of beauty when he states that beauty is literally "seeing reality;" 12 then again, he is convinced that the realm of beauty, a "place beyond heaven," is "a place without colors, without forms, and without solidity." 13 Obviously, such a contradiction at the core of his philosophy poses a colossal problem. How can we see what is invisible? Let us first note that the confusion was not merely his own: it preceded him in different forms, and it persisted all the way through Hegel's "sinnliche Idee"14 and Paul Klee's "art renders the invisible visible," to cite just two examples. Also, we should realize that the problem is more of a geometrical, dimensional nature than a conceptual or philosophical one. Without a doubt, Plato put all the elements in place: the vertical, the horizontal, linearity, circularity, the middle, the circumference-though the whole idea remains a tangle almost too discouraging to unravel. As stated, it would take thinkers a couple of thousand years to see that what looked like a pole was actually a line, and that what looked like a line was actually an axis, and what looked like one axis with two poles was actually two axes, and that those two axes were equated by a circle, and that the circle was a single line that had one pole in the middle. After a few millenia of aesthetic development traced beauty back in the center, we can conclude that Plato had been right all along.

The notion of beauty-as-the-highest is one we find in many variations, of course, especially under the Neoplatonic philosophers, such as Pseudo-Dionysius, Plotinus and Saint Augustine, who without exception were theologians. Nietzsche derisively called Christianity "Platonism for the people," ${ }^{15}$ which might not be completely accurate, except for the implicit argument that Christians took advantage of Plato's confusion. The image of God embodies fear as much as it does love, and this confusion goes back much further than the Christian interpretation of Platonism. For instance, Zeus was associated with lightning, thunder and weather in general, ${ }^{16}$ i.e., with what we would call the sublime, while his son Apollo was associated with the sun and the radiance of the beautiful. (I would not be the first to state that Christianity copied that model from the ancient Greeks. In fact, very early depictions of Jesus show him as beardless as Apollo, and with his head surrounded by the same radiant halo.) But let us not dwell too long on the mythological origins of Western theology. Since our interest goes out to beauty and navigation, we should focus on its dimensional structure and try to unravel the difference between beauty-as-the-highest and beautyas-the-middle. Longinus, who in the first century A.D. wrote Peri Hypsous-literally meaning "On the High" though generally translated as On the Sublime-makes extensive use of the thunder-and-lightning model to describe the epiphanic character of 
sublimity. Throughout the treatise, it is clear that Longinus aligns the sublime with greatness - a word he uses over and over - as well as with the power of lightning that strikes from above, moving the subject "out of himself" (ekstasis) and overpowering him with an "irresistible force." Let us disregard the fact that Longinus' argument lies in the realm of rhetoric, or art in general, since it makes no difference for the positioning of the sublime on the vertical axis whether we encounter it in words, in imagery, through standing in front of actual mountains, or through sitting at home contemplating the endlessness of the universe- the diversity of these examples is telling enough. Beauty, sublimity, ugliness, nobility-without exception, these aesthetic values are to be found in the realm of the natural as well as the artificial; therefore, no theory relying on the formal properties of these realms will be able to sufficiently define such values. What is remarkable is that what at first seem to be mere metaphors are in fact exact phenomenological descriptions of aesthetic feelings; and what is even more remarkable is that their precision does not lead to a phenomenology but to an ontological machinery of a perplexing geometrical exactitude. How else would it possible for things to be called "high" or "great"?

After Longinus was translated into French by Boileau in 1674, his book quickly landed in the hands of the English aestheticians, and it was they who developed the sublime and prepared it for the German idealists, who turned the high into the deep, first as Kant's Abgrund, then as Schelling's Ungrund. John Dennis, Joseph Addison, the Earl of Shaftesbury, Edmund Burke: over a period of a hundred years, English aesthetic philosophers took the sublime and refined it with notions such as that of enthusiastic terror, which they distinguished from common terror (a fear mixed with a feeling of admiration), and placed it in the realm of the unlimited, the majestic, and the stupendous, all direct descendants of Plato's black horse, the horse of divine madness, or as the ancient Greeks called it, enthousiasmos. But what in Plato was still an overlapping of two forms of beauty, the highest and the middle, now became more clearly distinguished: beauty was a smooth world of what Francis Hutcheson famously called "uniformity amidst variety," 17 while the sublime was a world of the unlimited and the unbound, of either enormous size (like mountains), indefinite size (like weather and storms), or infinite size (like endlessness itself). Even without elaborating on the issue, it is immediately clear how the variety of terminology led to Kant's "Analytic of the Sublime," in which the sublime is analyzed as formlessness ${ }^{18}$ or as the gap in judgment, be it in its mathematical state of the infinite or its dynamical state of pure forces without form. For our purposes, the younger Kant is of more use, since he drew, in particular, from the wealth of Burke's A Philosophical Enquiry into the Origin of Our Ideas of the Beautiful and the Sublime of 1757 and started to change its organization from a bipolar to a linear system.

Though in his Observations on the Feeling of the Beautiful and Sublime (1764) Kant is not as imaginative as Burke in introducing new aesthetic values, he is highly original at conceiving linkages between them. While in Burke's Enquiry all aesthetic examples are defined as subcategories of the two polar categories, we encounter a more complex systematization in Observations. As in Burke, we are told that mountains are sublime, as are Egyptian pyramids, and, in general, men more than women, but also black hair and all things related to the night, while small things are beautiful, and of course women more than men, as well as blond hair and delicate things bathing in daylight. The two colors of Plato's horses return even in human hair, defining the same distinction of ecstatic Rübrung and calming Reiz. ${ }^{19}$ As said, the increased systemacy of 
the Observations is of more interest to us, especially since it is based on what Kant calls Mischung, admixture. We should bear in mind that "admixture" is a concept closely related to Plato's metaxu, since it requires a continuum between two different states. With the term Mischung, Kant is able to articulate the existence of objects that are, for instance, less sublime and more beautiful, such as the splendid, das Prächtige. That notion of the splendid is then no longer a subcategory of the sublime, like Burke's magnificence, but a genuine category born of the parentage of mixture. Because of its direct relation to power and overpowering, Kant found the splendid in palatial and ecclesiastical buildings. Homonyms for splendid are "superb," "great," "grand," "magnificent," all referring unambiguously to size. Largeness is not merely a question of size; it necessarily follows the play of forces, and therefore structure is more visible than, say, a smooth skin. For example, Rome's St. Peter's basilica, Kant argues, has both sublime aspects, because of the colossal order of "its frame, which is large and simple," 20 and elements of beauty, such as the "gold and the mosaic work," and in their mixture we apprehend it as splendid. This is a discovery of great significance, though mostly overlooked by Kant himself, since it means that an object that has aspects of two aesthetic categories can be experienced in one feeling rather than through swinging back and forth between two. Such an insight could have led him away from subjectivism, because it emphasizes the singularity of the aesthetic object.

At the far end of the sublime, Kant posits the Schreckhaft-Erhabene, the terrifying sublime, followed by the noble (das Edle), and then by the splendid. Each of these moves further away from a pure sublime, mixing in more beauty, until we finally arrive at beauty itself, first in a more mature version, which still seems to contain some remnants of the sublime, and then in a juvenescent version he calls bübsch, pretty, a derivation of beauty that "speaks less to the heart." ${ }^{21}$ As often, though, next to admixtures we find Burkean subcategories of the sublime and of beauty, such as tragedy and comedy. Since in the Observations Kant is not trying to build a solid philosophical system, as he is in the three Critiques, it is rather difficult for the reader to distinguish between genuine aesthetic feelings and variants of such feelings. Gradually, however, we see the beginnings of a linear system emerging, not Plato's polar or Burke's bipolar model but a continuous line with at one end things that are smooth, vary gradually and are mostly smaller in size and at the other end things that are rough, vary more through angularity and sudden shifts and are larger. This resembles almost exactly the system used by Uvedale Price to position his notion of the picturesque as "a station between beauty and sublimity." 22 In 1796's On the Picturesque, he maps out exactly what the picturesque consists of:

Another essential quality of beauty is gradual variation; that is ... where the lines do not vary in a sudden and broken manner, and where there is no sudden protuberance: it requires but little reflection to perceive, that the exclusion of all but flowing lines cannot promote variety; and that sudden protuberances, and lines that cross each other in a sudden and broken manner, are among the most fruitful causes of intricacy. I am therefore persuaded, that the two opposite qualities of roughness, and of sudden variation, joined to that of irregularity, are the most efficient causes of the picturesque. ${ }^{23}$

Reading this carefully, we notice that Price describes the two not just as a pole of roughness and an opposing one of smoothness but also as two types of variation. 
Here, we get the first hint in aesthetic theory that things are combinations (equations, mixtures, metaxu) of two sliding scales, one of smooth and one of rough variation, one of graduality and one of suddenness. What first seemed to be a mere pole of beauty opposed to one of the sublime slowly develops into an axis of beauty, sliding between unity and plurality, and an axis of the sublime, sliding between maximum depth, i.e., the infinite, and minimum depth, such as prettiness. This would mean that less smooth does not automatically equate to more rough but that both smoothness and roughness consist of their own sliding scales, each influencing every object independently. We find another hint at such a theory in Hogarth's renowned Analysis of Beauty, which is generally taken as an argument for mere smoothness, since it stipulates the importance of the smooth, S-shaped serpentine line, which he calls the line of beauty. This is only partially correct, since in Hogarth's analysis these lines of smoothness and gradualism do not connect up smoothly:

there is one type of waving line that truly deserves the name of the line of beauty, only one precise serpentine line that I call the line of grace ... lines that should be judiciously mixed and combined with one another ... into [a joint sensation of bulk and motion]. ${ }^{24}$

Later in the book, when discussing contemporary women's hairdos, he calls the combination of smooth curves and criss-crossing wantonness "picturesque," 25 almost forty years before Uvedale Price used the term. And in his paintings and engravings he uses the same term for dancing groups, gatherings at dinner tables, and crowds in the street. In his introduction to the book, Ronald Paulson very aptly describes Hogarth's aesthetics as "an aesthetics of the crowd." ${ }^{26}$ The title The Analysis of Beauty suggests the desire to update the notion of beauty, though, not to introduce a new species, and to move away from the all-too-idealized, all-out smoothness of Giorgione or Titian, in which smooth lines do connect up smoothly. Hogarth tried to locate a new middle in the combination of roughness - what he calls "bulk" — and smoothness - "the line of grace." In Price and Hogarth, we encounter as yet only a suggestion of a biaxiality of the aesthetic system; we must wait almost 200 years to see it elaborated to its full extent in the realm of philosophy.

In that discipline, it was first Wilhelm Dilthey, the German neo-Kantian philosopher, who expanded Kant's selection of values, fitting in more of the terms that Burke had introduced. What makes his contribution particularly valuable is the introduction of the term "spectrum" in his discussion of the notion of mixtures. In 1887's Poetry and Experience, he writes:

To this mixture of the sublime, the tragic, and evil, ugliness can be added. Here we reach the limits of aesthetic impression. We represented the beautiful as the midpoint of a spectrum of poetic moods. ${ }^{27}$

Of course, we have just leapfrogged over the span of a full century, so by the time we encounter Dilthey, many details have been added to what we can almost start calling the aesthetic diagram. Aside from the term "mixture" reintroduced after Kant, we see that Dilthey has managed to finally position ugliness in the lineup; until then, ugliness had merely been a subcategory of beauty, and a negative one at that. The works of Victor Hugo, Dickens or Shakespeare would be unimaginable without their ugly 
characters, Dilthey argues; the narrative would simply not move forward. And he encounters the same positivity of the ugly in African masks and in Dante. To clarify, he is not making a judgment; neither judgment nor criticality plays an ontological role in aesthetics. Following the same line of argument, Charles Hartshorne states very clearly that there is no negativity in aesthetics, not even a zero, only positivity: ${ }^{28}$ there is no way we cannot experience; we might qualify our experience as "negative," but that is still a qualification and not a non-qualification. What is more, Dilthey speaks of a spectrum of values, which will prove to be important when we start to involve the color wheel as a system incorporating not only gradualism but also contrast and suddenness. And, he makes a far bigger effort than his predecessors to restore the notion of beauty-as-themiddle, repositioning it from one side of the spectrum to the center:

On both ends of the spectrum, whose middle is formed by the ideally beautiful, there arises an admixture of displeasure, and from a dissolution of the latter, a peculiar agreeableness. In one case, the feeling of something immeasurably great in the meaning of an object must be overcome; in the other case, the feeling of something trifling. ${ }^{29}$

He is onto something extraordinary here. After hundreds of years of aestheticians extending the range of the sublime, adding various types of terror, even of horror (in the case of Ann Radcliffe) ${ }^{30}$ he extends the range of beauty, not just with prettiness but many other aesthetic values, at least enough to shift beauty toward the middle. Though much of Kant remains in his analysis, Dilthey succeeds in including many of the values that Burke listed in his Enquiry, such as the ugly, the tragic and the comic, as Kant had failed to do. As with his predecessors, it is often difficult to precisely distinguish between categories and subcategories, but shifting back and forth, we can retrieve the following spectral sequence from Poetry and Experience: moving from one end to the other, we encounter the sublime, the tragic, the ugly, the beautiful, the sentimental, the comical, the graceful and the petite. At this point it is irrelevant whether or not we agree with this list. We merely need to acknowledge that what we called "minimum depth" a few paragraphs ago has now been extended by multiple values, with petite at the far end, in clear reference to the smallest possible size of things. "Trifling" also denotes a certain shallowness or superficiality, directly positioning it on an axis of depth, even though it indicates a lack of it. On the other hand, a spectrum of depths does not fit with Hutcheson's smooth spectrum that went from unity to variety, with everything in between and beauty in the middle. Evidently, organizing aesthetic values in a linear system presents serious limitations. For instance, we can see how the sublime might differ only one notch from the tragic, but to have the ugly removed likewise by a single notch from beauty seems improbable. The more existing aesthetic values we try to incorporate, the less a single dimension succeeds in explaining how middles and extremes are to be related. If everything is mixture, what is at the ends? Surely, if there are ends, they would be excluded from the mixture. But if we succeeded in removing the ends, where would that leave the middle? That said, the enormous contribution of Dilthey's spectrum lies in the inclusion of the ugly as a positive value and (re-)positioning beauty in the middle of the system.

Finally, in his Aesthetics and the Theory of Art of 1906, the German aesthetics theorist Max Dessoir turns the spectrum into a circle. A two-dimensional circle is capable of organizing values in a way the one-dimensional line of a spectrum cannot; it 
can include adjacent gradations, such as that between the sublime and tragic, as well as contrasting oppositions, such as that between beauty and ugliness. In Dessoir's book it is depicted in a very small diagram, no more than an inch in diameter, with six aesthetic categories aligned along the perimeter. The spectral line born out of Burke's bipolar system now becomes an aesthetic circle that runs from sublime to beautiful, to cute $(\text { Niedlich })^{31}$ to comic, to ugly, and finally to tragic, which links up again with the sublime (see fig. 1). Without going too far with our analysis, we should make a few remarks on Dessoir's terminology. In the first place, "cute" is a far better term than Kant's "pretty" or Dilthey's "petite." "Pretty" is not shallow enough, and "petite" not small enough, to occupy the position most contrary to the sublime. For instance, babies are cute, and for good reason: cuteness is the form beauty takes in situations where there is a complete lack of power, so as to restore that power. Cuteness merges the shallow and the likable into an overwhelming sweetness-again, a category acknowledged by Burke ${ }^{32}$ - which we recognize from our soda drinks and our obsession with sugar, as well as from the way lovers constantly address one another as "Sugar," "Sweetie" or "Honey." Cuteness plays a far more important role in our contemporary aesthetic than it did in Dessoir's time, when there was no Hello Kitty, no My Little Pony, no Mini or Swatch.
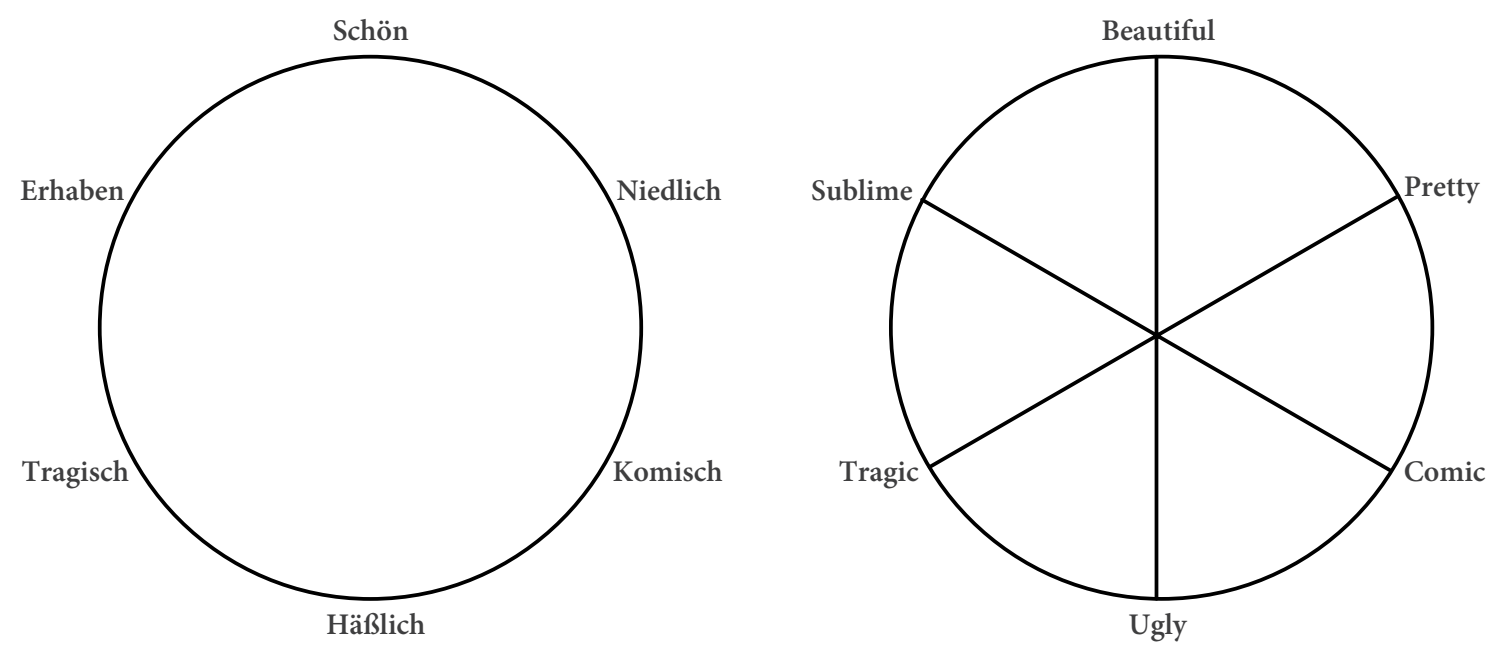

Fig. 1. The Aesthetic Spectrum as published by Max Dessoir. On the left is the original German version from his 1906 Ästhetik und allgemeine Kunstwissenschaft; on the right, the diagram as published in the 1970 English edition Aesthetics and Theory of Art (which mistranslates Niedlich as "pretty" instead of "cute").

On the other hand, when we compare Dessoir's circle to Dilthey's spectrum, some terms are missing, and some of the positionings are rather unconvincing. For instance, it is difficult to imagine the sublime and the beautiful as being adjacent to one another in the same way beauty and the cute are, nor akin in the way of the sublime and the tragic, whose link was thoroughly established by Schiller and Schelling. Nor can we imagine the sublime and the beautiful being as close as the ugly and the comic, though Dessoir's positioning of the ugly is again an enormous improvement on Dilthey's. The comic and the ugly have an intimate relationship that we recognize from a long history, starting with dwarves, hunchbacks and jesters in the European courts, hilarious and pitiful Falstaffs in the theaters, and the dumme August and stumbling clowns in the circus. Similarly, from the eighteenth century onwards, we witnessed the explosion of 
caricature, the ultimate science of elasticity-elongating noses, thickening lips, bulging eyes, widening heads, shrinking chins, and so on-which culminates in our own fabulous Mr. Bean, who is blessed with the most elastic face ever. As with Dilthey, we are for the moment only concentrating on the organizational geometry of the aesthetic system, and therefore we can overlook the misplacing of certain categories and the resulting sequential order. Crucial at this point is that Dessoir closes the linear sequence into a circle by merging the ends, creating a continuity of aesthetic values.

It is no accident that the circular system looks like a color wheel, as Dessoir himself remarks:

... the whole fabric of aesthetic feelings can take on various tints... ${ }^{33}$

Probably he chose six tints ${ }^{34}$ for his aesthetic circle because it resembled Goethe's color wheel of 1809 (see fig. 2 on the left), who, differently from Newton, based his color scheme on gradations as much as on opposites (or what Goethe called polarity). The English edition of Dessoir's book adds spokes to the circular diagram, making it look even more like a wheel. Dessoir, who explicitly mentions Dilthey's Poetry and Experience as the main source of his ideas, admirably managed to join the two ends of the spectrum, like the ouroboros biting its own tail. Above all, he writes, his goal was "to arrange the primary forms in such a way that the transition from each to the two adjacent ones occurs with conceptual ease, and those opposed in content are opposite in position." ${ }^{35}$ Again, it is an order that explains the two dimensions of existence in a way a straight spectral band cannot. We can read the circle rotationally, following the gradual change from beautiful to cute to comic to ugly, and we can read beauty as opposite to ugliness as well, since they are positioned directly across the center of the circle from each other. It coincides exactly with the color wheel, which we can read as a system that contains smooth, gradual variations, such as that between red and orange, as well as rough, complementary contrasts, such as that between red and green.

In the history of color theory, the circular diagram actually preceded the linear spectrum, since the latter is based on wavelengths in the electromagnetic realm that were not established until the nineteenth century. When we look back at the color wheel with the knowledge of electromagnetic waves, we should ask ourselves how it is possible that ultraviolet can occupy a position directly adjacent to infrared when the two are at opposite ends of the linear spectrum. The position of violet between blue and red is completely logical when we look at the color wheel, but not when we look at the linear band of colors of the electromagnetic spectrum. ${ }^{36}$ It is quite a mystery, and in the world of color theory there is no real answer to be found; it appears that color is a system in itself, independent of electromagnetic waves, and therefore necessarily takes on the shape of a closed circle. How else can the color corresponding to a wavelength of 380 $\mathrm{nm}$ (violet) fit next to the one corresponding to that of $720 \mathrm{~nm}$ (red)? What is discontinuous in the linear spectrum is continuous on the color wheel, solving all relations between colors as gradations, but without sacrificing the structuring oppositions. Circular color diagrams date back to medieval times, and though Aron Sigfrid Forsius made one in 1611 that contained much more detail, none of these exhibit the simplicity of Newton's color circle published in his 1704 Opticks (see fig. 2, right). It is not certain that Newton ever laid eyes on the diagram of Forsius, or how he came to bend the linear spectrum created by prism and rainbow alike into a circle. One reason why Newton created his circular diagram could be that he conceived it as a disk. 
With all the colors-and in his mind there were seven, which deeply disturbed Goethe, who preferred six-painted in the right sizes, the disk, when spun around at high speed, would change from multicolored to white. (There we are: white is the mixture of all mixtures, the middle of all mediation.) This was to prove his theory that white light could be broken into spectral colors by a prism. However, it doesn't explain the colors' order. Probably the final answer was given by Newton himself, who admitted that between red and blue we would see indigo, not just the violet we find in the prismatic range. ${ }^{37}$ None of these explanations is very satisfying. The perplexing fact remains that all colors can be arranged on a wheel, a solution far more convincing than the linear electromagnetic spectrum: it radically turns color into a world of its own, an autonomous system constructed by internal relations of gradation and opposition.
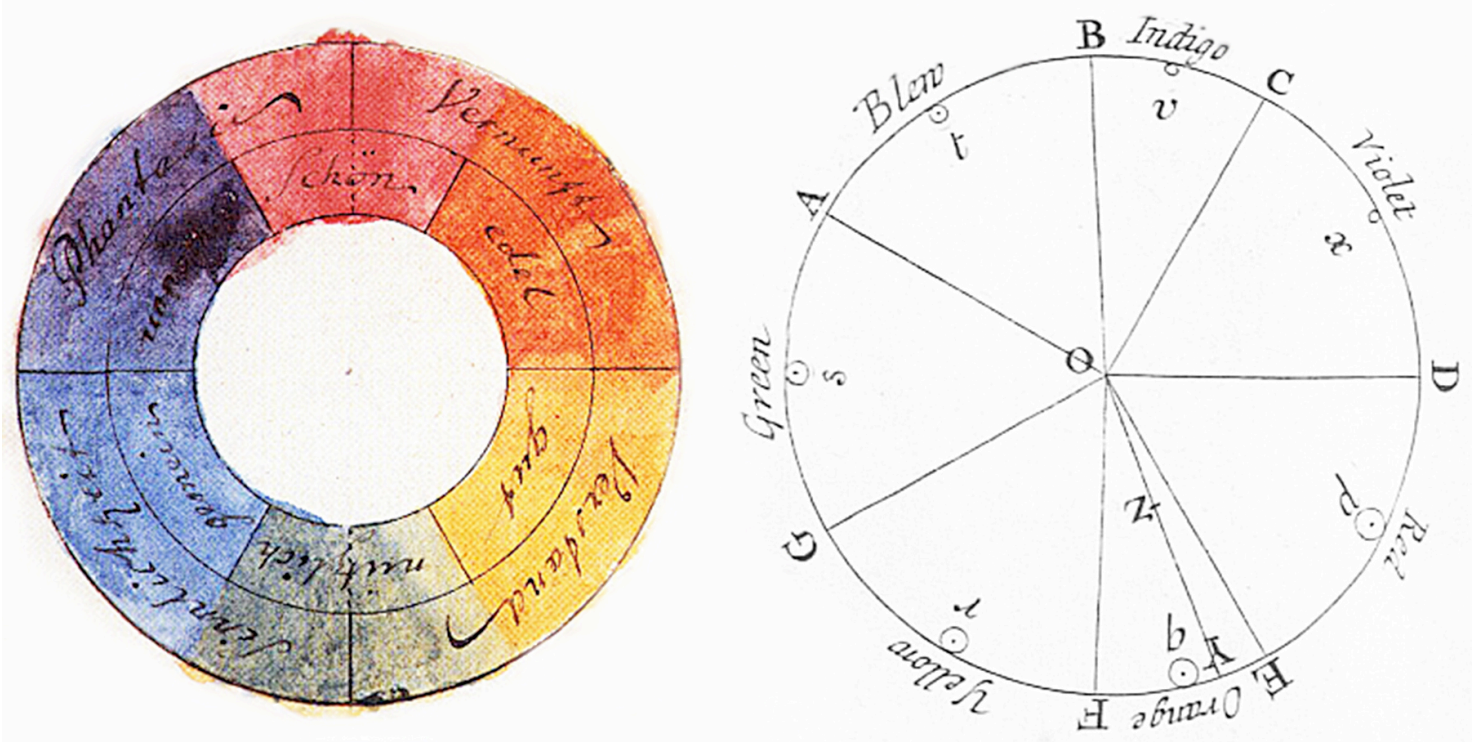

Fig. 2. The two most famous color wheels: on the left, Goethe's 1809 version with six colors (containing the term Schön in the red area); on the right, Newton's version from Opticks (1704).

The fact that we cannot explain something with concepts that are external to it means that, philosophically speaking, we have reached bedrock. A system that only consists of smooth, gradual variations would need an underlying, second system to adequately explain contrasts. And a system that consists only of fractures or rough variations would need a secondary system to explain kinship. It is mind-boggling to discover an ontological machinery based on continuity explaining the discontinuous, since it acknowledges polarity without having to rely on negativity. Nothing precedes color; no other systems are a priori to it: there is only the parallelism of other value systems, such as aesthetics, taste, smell and feeling, but no deeper ontology. What we generally view as mere peripheral, surface phenomena are actually structured in themselves, and therefore absolutely fundamental. Facts are made of value systems, or, as Whitehead put it: "... an actual fact is a fact of aesthetic experience." ${ }^{8}$ This not only means that color follows the structure of being but, more shockingly, the reverse as well, potentially creating a massive leak between aesthetics and ontology. In a nutshell: objects are constructed in the same system that we use to have feelings for those objects. And so subjectivism is the first to leave the scene, followed by negation, and then materialism-matter is simply what matters. 


\section{Compass and Wheel}

Before we move to the final stage in the development of a biaxial systemacy, in the form of Charles Hartshorne's Diagram of Aesthetic Values, we should take a brief look at the ideas on beauty of his primary influence, the Anglo-American philosopher Alfred North Whitehead. Like Hartshorne, Whitehead developed his ideas on beauty quite late in life, and not really until two of his last books, Adventures of Ideas (1933) and Modes of Thought (1938), published when he was in his seventies.

As I have discussed on earlier occasions, ${ }^{39}$ to define the nature of the two axes properly it is vital to understand Whitehead's argument, especially considering the history of aesthetic theories, which, by the way, both he and Hartshorne felt confident enough to omit. Beauty - "the teleology of the universe," as Whitehead phrased it ${ }^{40}$ consists of two dimensions, one of "mutual adaptation," the other of "patterned contrasts," ${ }^{41}$ or, in the words of Price, Hogarth and Burke, one dimension of smoothness and one of roughness. The axis of mutual adaptation (note the phrase's subtle evolutionary and environmental ring) indexes the necessity of harmonizing, that is, wholes harmonizing with other wholes; in short, the synthetic axis of smoothness, or extensity. The fact that it consists of an axis means that on the one end we find things that harmonize extremely, that are ultraunified, which Whitehead calls "minor beauty" or "the absence of a painful clash." 42 Meanwhile, on the other end, we find things that don't succeed in harmonizing, that is, things that are ultraplurified, what we call ugly. It is important to understand that the other term, contrast, is different from mere diversity, though. Things do not simply vary, they break away from each other. We see fractures emerging, sudden shifts and cuts (being literally analytic). Such contrasts and fractures often lead to layering and stratification with parts or groups of parts hiding behind one another, in what we often denote with "depth" or "profundity." Therefore, the effect of contrast is often expressed by magnitude, which is why we find the previously discussed greatness of the sublime on this axis, as well as the smallness of the cute at its opposite end.

This system allows every thing, every "occasion," every gesture to exist as a combination of smoothness and roughness, or in Whitehead's terms, massiveness and intensity. Here, massiveness refers to an index of coordination by gradual variation, and intensity to an index of the degree to which that coordinated whole allows its parts to be available to others. In themselves, there is nothing new in these remarks; we find them as readily in Uvedale Price or Edmund Burke. What is remarkable, however, is the fact that Whitehead does not put these on a single sliding scale, with massive, compact wholes on one end and loose, fractured ones on the other. Whitehead's doctrine is not just another take on Hutcheson's unity amidst variety. The parameters of massiveness and of intensity each have a uniform side and a diverse side; both are driven by variation, but each by a different type: one smooth, the other rough; one operating on adaptation, the other on contrast. ${ }^{43}$ Though he does not refer to prior aesthetic theories, which would have been helpful, nor visualize his system in the form of a diagram, which would have been even more helpful, he clearly views the system as a two-dimensional one, organized along two axes, each with minimum and maximum values at the ends. 
Eventually, by combining Whitehead's ideas on beauty with Dessoir's little diagram, Hartshorne took the final steps in his development of a diagram of aesthetics, an effort which can be traced over many years, beginning in the 1970s with Creative Synthesis and Philosophic Method, where he published the first version of what he then called the Dessoir-Davis Circle. As a diagram, it was strongly influenced by Dessoir's example from the beginning of the century, but the philosophy behind it owes far more to Whitehead. The version Hartshorne published in Creative Synthesis was a still-crude version of what he later, in 1987's Wisdom as Moderation, finalized as the "Diagram of Aesthetic Values" (see fig. 3). In these diagrams, Hartshorne made two essential adjustments to Dessoir's model, based on his readings of Whitehead: first, he repositioned beauty, and second, he added the superb, ${ }^{44}$ the neat and the commonplace..$^{45}$

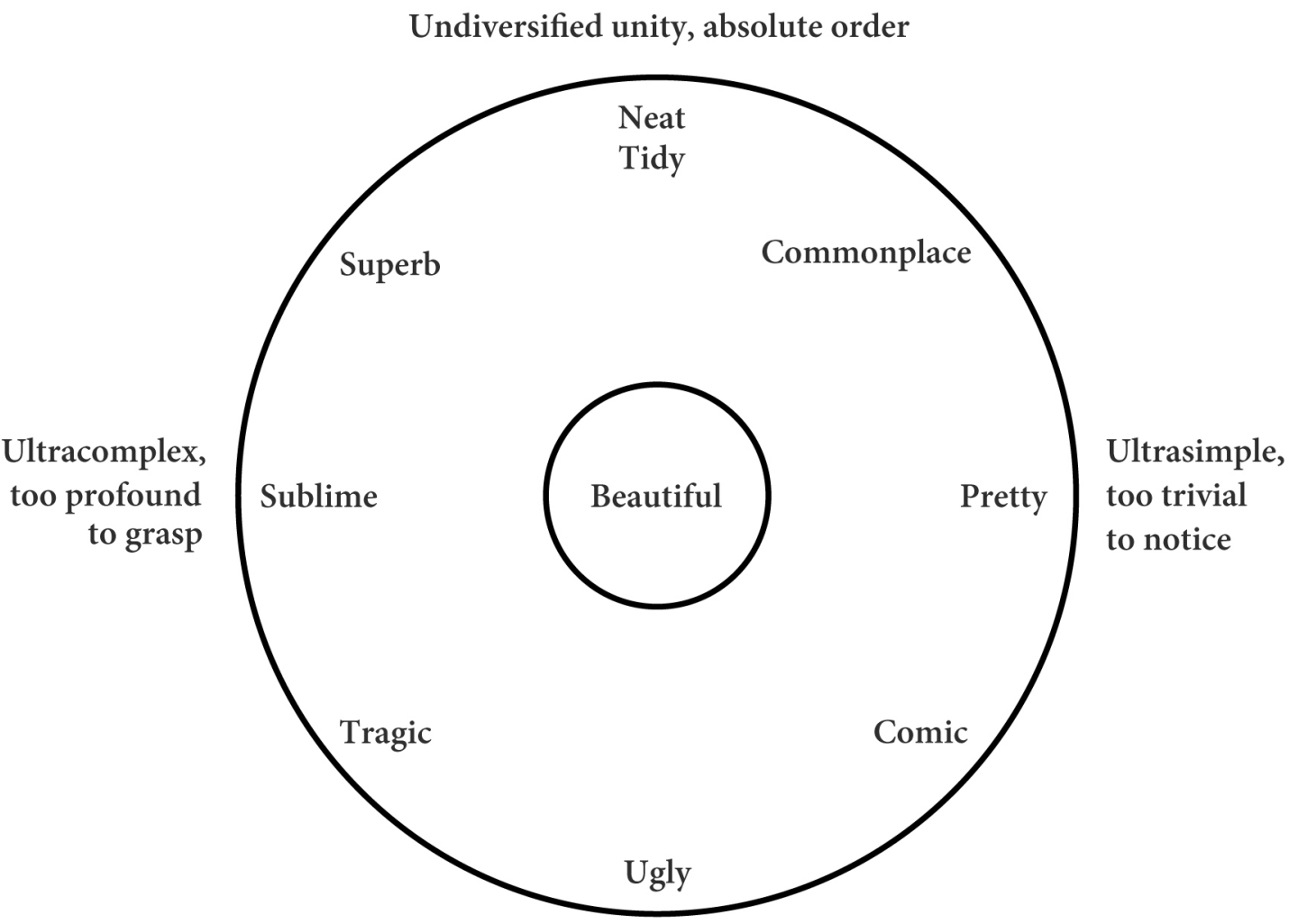

Ununified diversity, absolute disorder

Fig. 3. Diagram of Aesthetic Values (from: Charles Hartshorne, Wisdom as Moderation, 1987).

We should look at the repositioning of beauty first. It is quite clear that Whitehead's notion of beauty lies at the core of his process philosophy: things are only beautiful in their striving for beauty. Beauty is, above all, a teleological concept, since, as Whitehead himself said, "adaptation implies an end," 46 and while things strive to harmonize they can only do so by freeing their parts, allowing them to break away. Beauty, then, is not simply a state but a vector, similar to Apollo's arrow at the beginning of our discussion: each extensive act carries the need for intensity. Beauty inherently lies at the center of all this, as literally the target of every arrow, merging 
target with trajectory. It lies where the two axes intersect, and not where Dessoir located it, at the rim. Even though Hartshorne was deeply influenced by Whitehead, to actually position beauty at the center of a circle with two axes was a masterstroke. ${ }^{47}$ Thinking back to Plato's white and black horses, we can see how Hartshorne's model recasts the two forces as one striving for harmonization and the other for intensity. In Hartshorne's diagram, beauty is again firmly positioned in the middle, but the middle of a far more complex system that reconfigures Plato's monopolar, solar notion of beauty: "Beauty, in the most natural sense of the word, is the center, the double mean in both dimensions." ${ }^{48}$ Beauty is not a simple, singular middle, but a middle trying to find another middle.

Along with his Platonic repositioning of beauty, Hartshorne added three new categories to Dessoir's six, one of which he called "superb" - an idea we have already come across in Burke, in the form of magnificence, as well as in Kant, in the form of the Prächtige — and the other two "neat" and "commonplace." The latter two are crucial additions: "neat," though not a wholly satisfactory term, has connotations of monotony and boredom, while the commonplace corresponds to the normal or ordinary. With these, Hartshorne completely rearranges-repairs-the top half of Dessoir's model. It can be no accident that these final categories were added in the twentieth century, the age of the media and the masses. Before then, the concept of the commonplace was known mostly in the form of vulgarity, which at best ended up being associated with the comic. But in its modernist form, it points to a blandness and a complete lack of qualities that is truly original. The neat, better known in the form of boredom, is far older and, as ennui, was even considered an art by the likes of Charles Baudelaire and Beau Brummell (who famously turned to his valet to ask which of two lakes he admired most. $)^{49}$ Andy Warhol, the twentieth-century champion, if not saint, of boredom, made an eight-hour movie of the Empire State Building filmed in real time over a single night, appropriately titled Empire. He also loved to spend his holidays in Sweden, because, as he said, "in a place like that you can get so bored." ${ }^{50}$ The closest category from ancient history would probably be the decadence of the late Roman Empire as described in Petronius's Satyricon. With Hartshorne's circle, the aesthetic spectrum seems to transform into a continent, a planet even, where the spectral lines of Kant, Dilthey and Dessoir form partial routes or complete equators. Hartshorne's addition of the neat and the commonplace created a "north passage" at the top of the diagram similar to sixteenth-century attempts to expand shipping routes from Europe.

With his Diagram of Aesthetic Values, we can finally go full circle: reading clockwise, we encounter the sublime, the superb, the neat, the commonplace, the pretty, the comic, the ugly, the tragic and finally the sublime again. We should make a few adjustments, however. The superb is not as convincing as magnificence; the latter has more historical roots that go deeper and wider than superb, which dates back no further than the Renaissance. The neat should be substituted with the boring; again, its history is just too powerful, as we saw above, to say nothing of the celebrated elaborations of Martin Heidegger and Erich Fromm on the topic. The other replacement should be for the pretty, which we should exchange for the cute, which is conceptually stronger, and more correct opposite the sublime. Hartshorne seems unaware of Dilthey's categorization of "trifling” coinciding with his own qualification of the pretty as bordering on the "too trivial," and how Kant's notion of the Hübsch preceded these. Oddly enough, Hartshorne never discusses any historical precedents or developments of the circle or its terminology. Therefore, the final circular lineup will 
be: sublime, magnificent, boring, commonplace, cute, comic, ugly, tragic, and back to sublime. Although Hartshorne never bothered to draw the actual axes and only indicated the four poles in additional captions, we should include these in the revised diagram as well: a horizontal axis spanning from sublime on the left to cute on the right, and a vertical axis from ugly at the bottom to boring at the top (see fig. 4). Together they create the structure of a wheel or compass. It moves from the silent scream of the sublime to the exalted cry of the magnificent to the yawning mouth of boredom to the flat expression of the commonplace to the gentle smile of the cute to the outright laughter of the comic to the disgusted "ick" of the ugly, on to the weeping of the tragic, and back to the noiseless gasp of the sublime. We could play these facial expressions as an animation and we wouldn't be able to discern any jumps or cuts. And it all works because beauty has been taken out of the sequence: the relations between all these aesthetic values are wholly different than those between them and beauty. We have eight aesthetic categories that occur on the outer rim of aesthetics, connected by spokes of gradually decreasing value to the hub of beauty, which is in fact a ninth one, or the first, whichever one prefers. That the system in its final form looks like a compass reflects both meanings of the word: a limited, finite structure such as a planet as well as an instrument for navigating that planet.

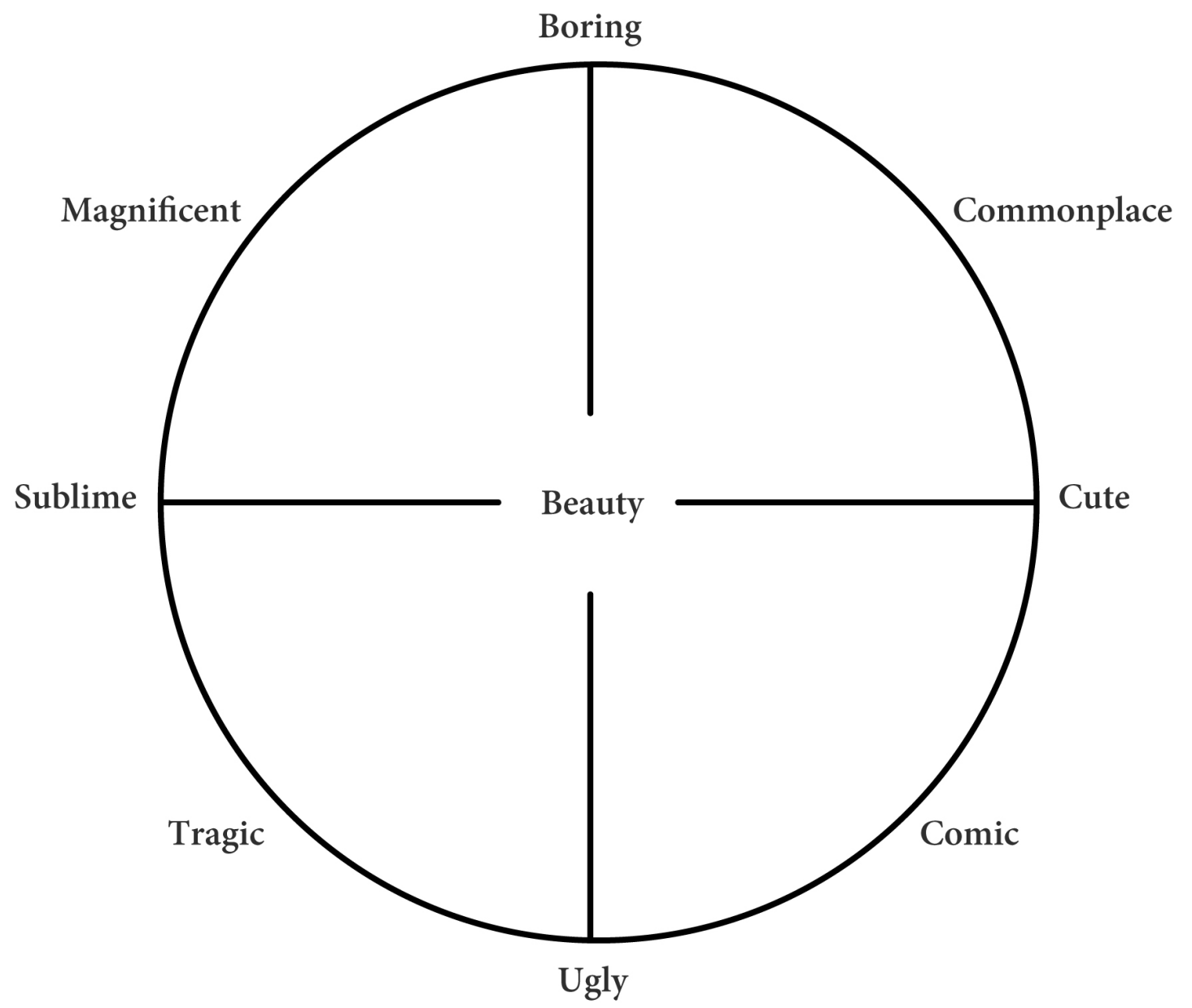

Fig. 4. The Compass of Beauty (adapted from Hartshorne's diagram to include the biaxial system and a revised terminology). 
Translated back into the color wheel, this would give us the standard hues at the outer edge of the circle, with more brightness mixed into each color until it becomes pure white light in the middle. (Plato's solar model of beauty was probably no accident.) Now we should also be able to find a place for every nameable aesthetic value on this circle, since feelings can vary in all directions, both rotationally and radially. We should have no problem finding positions that are located neither at the center or at the rim but occupy the as-yet-undefined area in between-the quirky, the quaint, the weird, the cool, the elegant, the vulgar, the melodramatic, the horrific, the gruesome, etc.-but that is an argument we will save for later.

When we fast-forward through the history of beauty, the first peculiarity that attracts our attention is that it started with Plato, who hated art, then developed through aesthetics, with indispensable contributions by artists, and then moved away from art again. For example, I think the Large Hadron Collider and the Saturn V rocket are more sublime than paintings of mountains, far more abstract and far more violent. And football stadiums are more magnificent than Kant's St. Peter's, and when a wave performed by 80,000 spectators moves over the stands, we are overpowered and swept away-to use Longinus's terms - by sheer awe. General Tommy Franks also called his invasion of Baghdad a strategy of "shock and awe," leaving no misunderstanding about where we should locate the sublime in our own age. I think there is more terror and horror in the daily imagery of suicide bombings than in Alien, Friday the $13^{\text {th }}$ and The Texas Chainsaw Massacre put together. There is more of the commonplace and the ordinary in reality television, in the endless soap operas and in Facebook posts than in the street life of Baudelaire's Paris. And if you type "beauty" into your search engine, you won't find the work of contemporary artists but a zillion websites related to the cosmetics industry. And who is not cute today (though no society goes as far as the Japanese with their kawaii)? It seems that art is playing an ever-smaller role-and the media an ever-larger one-in the development of the diagram, and especially in how it organizes the distribution of objects. Was Plato right again? Permit me to leave that as an open question.

In any case, what becomes evident in the developments over the last fifty years is that they show the ontological nature of the diagram more prominently. It is also clear from these developments that we seem to be living in an era that is expanding the diagram at high speed while moving away from its middle with equal speed. We live in an age of design: not just the design of objects but of events, concepts and issues, of organizations and procedures, even of our own lives. One's own life has become a project. The number of things is growing exponentially, and growing exponentially further away from beauty. If the diagram concerns all things, not just works of art, we should realize that it concerns them through beauty. This is the true power of Hartshorne's Diagram of Aesthetic Values: only beauty can relate the vertical axis to the horizontal one. The two axes are not independent; they don't form a mere coordinate system. If they were independent, the diagram would not be a circle but a square, and we could simply combine one extreme with the other, which goes against the whole notion of a middle. A square is not an equation; a circle is. We should keep in mind that even the sublime in Hartshorne's diagram is plotted halfway against the vertical 
axis of harmony and coordination. The fact that the influence of each axis always needs to be mediated makes beauty more than simply the middle of a circular world: it reverses the roles and makes the periphery a derivative of the middle. Both areas are circles: a white one in the middle and a multicolored one at the outskirts.

I don't have to stress the fact that Hartshorne's diagram shares many traits with the cruciform structure of Heidegger's fourfold; the similarities are quite obvious. They share the same purpose: to divide Being according to two axes, one spanning the space between the unified (boredom) and the plurified (ugly), the other between the deep (sublime) and the shallow (cute). ${ }^{51}$ Of course, Heidegger does not define the fourfold by the axes but by the four quadrants, which he identifies as sky, mortals, gods and earth. This is telling in a way, because by defining the quadrants he makes it impossible to view the axes as productive. The fourfold remains a static architectural system, a Geviert, and though he sometimes speculates about one quadrant mirroring the other, and even about a "round dance," 52 it never attains the status of an ontological machine equipped with dynamic sliders. Viewing the intersection of the axes as a hub, and identifying that with beauty, causes the compass to take on the character of a wheel more than a cross. Heidegger's Being always takes an unmoving, neutral position, humming in the background, whereas Whitehead's and Hartshorne's beauty thrusts things forward into presence. From the perspective of the Diagram of Aesthetic Values, the four quadrants can never be primary because they are parented by two axes. All activity lies with the axes, and they are bound to one another, limiting each other's influence to a circular field of existence-what I earlier called the arena of presence. Heidegger strongly resented the notion of being as presence ${ }^{53}$ and attempted to extend the phenomenal world to absence (e.g., the negativity of nothingness and the invisibility of Zubandenheit), to things happening without passing through consciousness. Certainly, no one would deny that things exist before they enter human consciousness, but that doesn't mean reality condemns things to roam around in darkness. On the contrary, it means things can claim light and consciousness in their own right: nonhuman thought and unseen light. Things think before we think them (how else could we understand things?), they are visible before we see them (how else would we see them?), and they affect their environment before we feel them (how else would we find them beautiful?). Again, the way the existence of things is constructed cannot be fundamentally different from the structure of our feelings; this is what the Diagram of Aesthetic Values teaches us. ${ }^{54}$

When we take a careful look at the diagram, we can better see how process and product not only are combined but are combined symmetrically only in the middle and asymmetrically everywhere else (though still equated). When we go back again to stand in front of St. Peter's with our faces upturned and our mouths open in admiration, it is the magnificent structure that overwhelms us. If we move from the basilica's position of magnificence vertically down on Hartshorne's map, we encounter figures such as Macbeth and Michael Jackson, obliterated by the tragic events they have instigated. At the position of magnificence, it is the massive structure that overwhelms us, and at the position of the tragic, it is the enormity of the events overwhelming their subjects: exactly the same magnitude in very different dimensions. This is why we recognize the top area of the diagram - the realm of magnificence, boredom and the commonplaceas the general territory of structures, or what Mikel Dufrenne called the spatial arts, and the bottom area-the realm of the tragic, the ugly and the comic-as the zone of events, or again in terms of aesthetics, the temporal arts. ${ }^{55}$ That doesn't mean buildings 
"are" boring; it means that when time is stopped they become boring, as in Warhol's Empire, where the Empire State Building is boring because you are trapped in your seat. (If you are walking in New York, the Empire State Building is anything but boring.) Or think of the funny example of Heidegger stuck in a provincial railway station after missing a train. ${ }^{56}$ Forced to wait for four hours, he started walking up and down the platform like a pendulum, hopelessly trying to restore time, like a panther in a cage. Inversely, the asymmetry of space and time means that the positivity of ugliness functions very well in plays, literature and movies but not in architecture. While in a gangster movie a character like Al Capone boosts the speed of events by bashing in heads with a baseball bat, an ugly building does not have the same positive effect on urban space. That doesn't mean a building can't be ugly; obviously it can, and a play can as easily be boring - that is not my point. In the specific case of a boring play, I think it exposes too much architecture, for example when it lacks development and has cardboard characters that move through the drama without changing. Similarly, a building is ugly when it tries to be funny or becomes too theatrical, since the chances are that we will encounter it more than once, killing all possible humor, or that we will experience it from more than one angle, destroying every illusion.

On the product side, things have to be looked at in terms of how they relate to time; from the process side, they have to be looked at in terms of how they relate to space. Beauty is not organized by going from product to product nor from process to process, but from process to product and from product to process and back again. Ours is a jerking, jolting universe. If aesthetics operated within one dimension, a single line of variations and gradations would suffice. If it consisted merely of spatial encounters, things would simply shape each other from the outside and the synthetic axis would do all the necessary work. And if it solely consisted of events meeting one another, all would be pure development; the internal growth of things would never lead to them being born into the world. In the Diagram of Aesthetic Values, these two lines are bound to one another as axes, with both rather than one or the other exerting their influence on the final product. When things are formed, they are internally driven by a force occupying the analytic axis of intensity, while they simultaneously orient themselves in and adapt to an external world whose powers are expressed along the synthetic axis of the extensive, i.e., present themselves as forms. Things present themselves in one realm, but they cannot be explained through one dimension, only through the conflation of two dimensions.

Stand in front of a 400-year-old oak tree. Its structure-the branchings, the bifurcations, the random curvature-all this is pure process, pure time and growth. But does it present itself to us as time? Do we experience it as time? No, we experience it as sheer magnificence. All that was time is presented to us as beauty, and all that is beauty we experience in time, yes, but the second stretch of time is wholly discontinuous with the first. In this sense, beauty is purely Platonic, atemporal stoppage.

\section{Endnotes}

\footnotetext{
${ }^{1} \mathrm{Cf}$. the very last sentence in The Origin of Species.

${ }^{2}$ See: Lars Spuybroek, "Charis and Radiance: The Ontological Dimensions of Beauty," in: Giving and Taking: Antidotes to a Culture of Greed (Rotterdam: V2_Publishing, 2014), 118-49.

${ }^{3}$ Heraclitus, Fragment 51.

${ }^{4}$ Odyssey, XXI: 411.
} 
${ }^{5}$ Karl Kerenyi, Apollo: The Wind, the Spirit and the God (Dallas: Spring Publications, 1983), 58.

${ }^{6}$ Marcel Detienne, “Apollo’s Slaughterhouse," in: Diacritics, Vol. 16, No. 2 (Summer, 1986), 51.

${ }^{7}$ Symposium 201e and 204b.

${ }^{8}$ Symposium 204e.

${ }^{9}$ Phaedrus 254b.

${ }^{10}$ Phaedrus 251c.

${ }^{11}$ Phaedrus 251a.

${ }^{12}$ Phaedrus 248b.

${ }^{13}$ Phaedrus 247c.

${ }^{14}$ G.W.F. Hegel, Vorlesungen über der Ästhetik, I.I.3, Die Idee des Schönen: "Das Sinnliche Scheinen der Idee."

${ }^{15}$ Friedrich Nietzsche, from the preface to Beyond Good and Evil. In the original German: "Christentum ist Platonismus für's 'Volk'."

${ }^{16}$ Walter Burkert, Greek Religion (Cambridge, Mass.: Harvard University Press, 1985), 126.

${ }^{17}$ Francis Hutcheson, An Inquiry into the Original of Our Ideas of Beauty and Virtue (1725), I, 2, 3.

${ }^{18}$ Immanuel Kant, The Critique of Judgment, \$24.

${ }^{19}$ Immanuel Kant, Observations on the Feeling of the Beautiful and Sublime (Berkeley: University of California Press, 1991), 47. In the original German: "Das Erhabene rührt, das Schöne reizt."

${ }^{20}$ Ibid., 49.

${ }^{21}$ Ibid., 87.

${ }^{22}$ Uvedale Price, On the Picturesque (Edinburgh: Caldwell, Lloyd \& Co.,1842, orig. 1796), 90.

${ }^{23}$ Ibid., 82.

${ }^{24}$ William Hogarth, The Analysis of Beauty (New Haven: Yale University Press, 1997), 51 and 73.

${ }^{25}$ Ibid., 35: “... the present fashion the ladies have gone into, of wearing a part of the hair of their heads braided together from behind, like intertwisted serpents, arising thickest from the bottom, lessing as it is brought forward, and naturally conforming to the shape of the rest of the hair it is pinned over, is extremely picturesque."

${ }^{26}$ Ibid., xvii-lxii.

${ }^{27}$ Wilhelm Dilthey, Poetry and Experience (Princeton: Princeton University Press, 1985), 146.

${ }^{28}$ Charles Hartshorne, The Zero Fallacy (Chicago: Open Court, 1997), 204.

${ }^{29}$ Dilthey, Poetry and Experience, 145.

${ }^{30}$ Ann Radcliffe, "On the Supernatural in Poetry," in: The Nerw Monthly Magazine (1826), 145-52.

${ }^{31}$ The English edition (Detroit: Wayne State University Press, 1970) mistranslates niedlich as "pretty" instead of "cute" (p. 150). Cf. the original diagram in: Max Dessoir, Ästhetik (Stuttgart: Ferdinand Enke Verlag, 1923; orig. 1906), 139.

${ }^{32}$ Edmund Burke, A Philosophical Enquiry into the Origin of our Ideas of the Sublime and the Beautiful (Oxford: Oxford University Press, 1998), Section XXI and XXII.

${ }^{33}$ Dessoir, Aesthetics and Theory of Art, 149.

${ }^{34}$ In the original German, the word is "Färbungen," of which "colorations" or "colorings" would be a better translation than "tints."

${ }^{35}$ Ibid., 150.

${ }^{36}$ See: John Gage, Colour and Culture (London: Thames and Hudson, 1995), 171: “Newton's colourmixing diagram ... has a clear inner coherence because it was simply an attempt to roll up the prismatic spectrum."

${ }^{37}$ Isaac Newton, Opticks, Book I, Par. II, Tab. III, fig. 11.

${ }^{38}$ Alfred North Whitehead, Process and Reality (New York: The Free Press, 1978), 280.

${ }^{39}$ Lars Spuybroek, “The Ages of Beauty: Revisiting Hartshorne's Diagram of Aesthetic Values," in: Vital Beauty: Reclaiming Aesthetics in the Tangle of Technology and Nature (Rotterdam: V2_Publishing, 2012), 32-60.

${ }^{40}$ Alfred North Whitehead, Adventures of Ideas (New York: The Free Press, 1967), 265.

${ }^{41}$ Ibid., 252.

${ }^{42}$ Ibid., 252.

${ }^{43}$ The two dimensions of smoothness and roughness, or massiveness and intensity, correspond directly to Ruskin's organization of Gothic aesthetics in terms of changefulness and savageness, as I have discussed in the first chapter of The Sympathy of Things ( $2^{\text {nd }}$ ed., London: Bloomsbury, 2016).

${ }^{44}$ Hartshorne changed it from "magnificent" in 1970 to "superb" in 1987. 
${ }^{45}$ Hartshorne borrows the term "commonplace" from Whitehead. See: Adventures of Ideas, 261.

${ }^{46}$ Whitehead, Adventures of Ideas, 252.

${ }^{47}$ Actually, the idea to take beauty from the rim and move it to the middle came from Kay Davis-

Leclerc, one of his students at Emory University. Hartshorne mentions this in several of his books but gives slightly different versions of the story. In The Zero Fallacy (p. 203), he suggests that the diagram was a collaboration between him, Dessoir and Davis-Leclerc, but this can be true only in an abstract sense: Dessoir died in 1947 in Frankfurt and never met Hartshorne. Hartshorne most probably saw Dessoir's diagram for the first time in 1970, when the English translation of the latter's work was published. This assumption is supported by the fact that Hartshorne adopted the mistranslation of Niedlich as "pretty" in his own diagram. Davis-Leclerc was his student in the 1950s, but not by the time he published Creative Synthesis, where the diagram is presented in the final chapter.

${ }^{48}$ Charles Hartshorne, Wisdom as Moderation, 2.

${ }^{49}$ Carlo Maria Franzero, Beau Brummell: His Life and Times (New York: John Day Co., 1958), 71.

${ }^{50}$ The Philosophy of Andy Warhol (Orlando: First Harvest, 1977), 72: "When you're in Sweden \& you see beautiful person after beautiful person \& you finally don't even turn around to look because you know the next person you see will be just as beautiful as the one you didn't bother to turn around to look at-in a place like that you can get so bored that when you see a person who's not beautiful, they look very beautiful to you because they break the beautiful monotony."

${ }^{51}$ Graham Harman, Heidegger Explained (Chicago: Open Court, 2007), 132-5.

${ }^{52}$ Martin Heidegger, Poetry, Language, Thought (New York: HarperCollins, 2001), 178.

${ }^{53}$ Harman, Heidegger Explained, 1.

${ }^{54}$ To give an example: it means that I think a sunset is actually there, and beautiful, without anybody seeing it-a thought that would horrify any (neo-)materialist.

${ }^{55}$ Mikel Dufrenne, The Phenomenology of Aesthetic Experience (Evanston: Northwestern University Press, 1973), 239-48.

${ }^{56}$ Martin Heidegger, The Fundamental Concepts of Metaphysics (Bloomington: Indiana University Press, 1995), 93. 